\title{
O Universo poético de Vitória Basaia
}

\author{
http://dx.doi.org/10.1590/1984-0292/1325
}

\section{Alexandro Uguccioni Romão, José Serafim Bertoloto ${ }^{\star}$} Universidade Federal de Mato Grosso, Cuiabá, MT, Brasil e Universidade de Cuiabá, Cuiabá, MT, Brasil

\section{RESUMO}

A artista plástica Vitória Basaia é capaz de parir mundos usando matérias primas refugadas pela sociedade. A Casa Basaia é o seu local de moradia e também o seu ateliê. A casa se transformou ao longo dos anos em uma espécie de museu. Nesse artigo, sondamos esse universo a partir da análise das obras, materiais, técnicas e preocupações ontológicas da artista relacionadas à criação. Com base em conceitos de autores como Deleuze, Guattari, Bertoloto, Bachelard e Brandão, observamos como a inquietação da artista se converte em programa de arte e constitui o seu universo poético, territorializado na Casa Basaia.

Palavras-chave: Vitória Basaia; poética; artes plásticas, artes.

\section{The POetic Universe of Vitória Basaia}

\begin{abstract}
The artist, Vitória Basaia, is able to give birth to different worlds using raw materials refused or withdrawn by society. The Basaia House is her place of residence and also her studio. The house has been transformed into a sort of museum over the years. In this article, we explore this universe based on analysis of her works, materials, techniques and ontological discussions regarding the artist's creation. Based on concepts from authors such as Deleuze, Guattari, Bertoloto, Bachelard and Brandão, we observe how the artist's restlessness becomes into art program and consists in her poetic universe, territorialized in the House Basaia.
\end{abstract}

Keywords: Vitória Basaia; poetic; plastic arts; arts.

^Endereço para correspondência: Universidade de Cuiabá. Avenida Beirario - Jd. Europa. 78000000
- Cuiabá, MT - Brasil. E-mail: omao.mkt@gmail.com, serafim.bertoloto@gmail.com 
A arte disponibiliza variadas interpretações intelectuais e distintas experiências sensoriais, tanto de quem a faz, como de quem a contempla ou interage. Podemos, por exemplo, abordá-la com base na estética iniciada pela experiência contida na fruição da obra. Nesse artigo, nos restringimos a observar os elementos que gravitam pela maneira da artista plástica Vitória Basaia produzir suas obras e por consequência criar um universo ao seu redor. A partir do modo de produção das obras, sondamos as redes simbólicas que tecem o universo poético da artista.

Neste contexto, observamos o universo construído por Basaia, por meio da análise de sua poética, na busca por identificar o seu programa de arte e suas conexões com mundo. Entender o modo como a artista produz arte é derivar pelos elementos que compõem o seu mundo, é transitar pelas partes e pelos fragmentos de sua obra e de sua vida, na tentativa de seguir as teias e as redes que revelam o todo do seu universo.

Vitória Basaia é uma artista que possui uma vasta produção, suas obras estão dispostas ou guardadas em sua casa, transformada em um verdadeiro "museu". Ela possui uma obra extensa e diversificada. A obra da artista se destaca, quando comparada com o trabalho de outros artistas da região de Mato Grosso, por expandir os parâmetros culturais, que, de forma geral, categorizam os artistas mato-grossenses.

Nosso olhar se debruça sobre a obra de Vitória pelo viés do conceito de poética, com o objetivo de apresentar os aspectos particulares disponibilizados por seu trabalho artístico. Utilizamos o conceito de poética cunhado pelo pesquisador italiano Luigui Pareyson (2001) em sua obra Os problemas da estética, na qual conceitua poética como sendo um programa de arte, um modo de produção da atividade artística normatizada por um gosto específico, trazendo à tona toda a espiritualidade de um artista ou de uma época (PAREYSON, 2001, p. 11). Assim, abordamos a criação do universo de Vitória Basaia, analisando a maneira como ela produz arte com foco principal na construção de sua grande obra: a Casa Basaia, pedaço de terra que abriga o universo da artista.

Vitória Basaia cria obras distintas a partir do seu modo de produção, calcado no processamento de diversos materiais, seja eles refugados ou naturais, como, por exemplo, a terra transformada em tinta para criação de seus desenhos. A pesquisa plástica com refugos é uma característica da sua produção artística. Basaia utiliza matérias primas obsoletas que foram descartadas pela sociedade de consumo. Nesse contexto, a artista afirma que: "qualquer material pode se transformar em obra de arte" (BASAIA, 2012, entrevista).

A artista além das obras, cria ao seu redor um universo mítico que explica a sua necessidade de produzir arte. Essa mitificação de sua poética gera uma cosmogonia, uma maneira de relatar a criação do mundo conferindo ao nascimento do cosmos uma explicação, conforme afirma Chevalier (1993, p. 295) em seu livro Dicionário de símbolos. A Casa Basaia é o centro desse universo, território no qual a cosmogonia da artista tem origem. Ela é a sua obra principal, pois sintetiza sua poética e se constitui simbolicamente na própria Vitória Basaia, ao mesmo tempo em que abriga o seu universo poético. 


\section{Vitória Basaia}

Vitória Basaia pode ser considerada uma das mais singulares artistas em Mato Grosso nas últimas duas décadas. Traços que garantem essa singularidade são notados, com facilidade, tanto em sua obra quanto em sua personalidade. A respeito de sua vida, Vitória Basaia, que merece uma dedicada biografia a ser feita posteriormente, tem na força feminina seu traço mais distintivo.

Entendemos força feminina como uma forma de fazer a vida e a arte rompendo com padrões sociais estabelecidos para a mulher. Vitória se construiu no espaço público e privado como ser vivo original. Ela buscou a transgressão da desigualdade entre os gêneros, ao mesmo tempo em que destacou as questões próprias a fisiologia feminina (a gestação e o parto), como marca de seu discurso e, principalmente, da sua prática artística.

Vitória, antes de tudo, é um ser inquieto e obstinado pela criação. Em termos mais precisos, considerando os traços de sua poética, a artista é "obstinada" pela gestação. Em seus desenhos, seres femininos posam nus, com os seios e a vagina à mostra, que nos remete ao caráter sexual e materno do ser feminino. A gestação não está apenas nas obras, mas na forma de produzi-las. A artista mitifica a sua criação ao referir-se ao seu processo de criação utilizando a metáfora da concepção feminina. $\mathrm{O}$ instigante não é a percepção inicial da inquietação, eminentemente feminina, mas a investigação de como essa condição é entalhada em sua personalidade, a partir da sua trajetória, e manifesta-se de forma definitiva em suas obras.

Nascida no Rio de Janeiro no dia 15 de setembro de 1956, Vitória Basaia "é uma artista que não nasceu em Mato Grosso, mas a sua integração participativa dá-se, de forma tal, que em momento nenhum a consideramos estrangeira". (BERTOLOTO, 2006b, s/p). Possivelmente ela tenha nascido uma carioca forte, com possibilidades de se afirmar naquele contexto e cultura, mas foram suas escolhas e as consequências destas que potencializaram esse traço.

Ainfância da artista foi envolvida por uma áurea criativa e fortemente lúdica, promovida pelo ato de brincar, contar histórias e fazer os próprios brinquedos, atividades que ocorriam no seio familiar e eram motivadas em especial por sua avó materna. Vitória passou a infância em Goiânia por contingência da profissão de seu pai, militar, mas manteve o vínculo com o Rio de Janeiro, primeiro pelas frequentes estadias na casa dos avós maternos e, depois, com idade escolar, pelo período em que morou naquela cidade para iniciar os estudos no primário. Sobre esse contexto de sua trajetória, a artista relata:

Sempre fui criativa, tive uma avó daquelas, assim, que transformava a sua mão numa boneca e que tudo ela criava. Contadora de histórias, tanto é que todos meus meninos são contadores de história, são superlúdicos, né!? Adoram crianças. Então tudo pra mim começa com um lazer, como uma brincadeira. Então a vida inteira eu fui arteira, né!? Eu sempre fui arteira, pegava uma coisa, 
brincava, desenhava, criava coisas, criava os próprios brinquedos (BASAIA, 2012, entrevista).

A partir deste depoimento, podemos considerar que as atividades lúdicas foram elementos importantes na formação subjetiva da artista. Atualmente, esses elementos estão contidos em sua poética e transparecem no modo como ela produz as suas obras. Separamos uma obra (figura 1), que nos possibilita verificar elementos lúdicos da poética da artista, cuja influência foi motivada pelas brincadeiras de criança, quando a menina Vitória produzia suas próprias bonecas motivada pela avó.

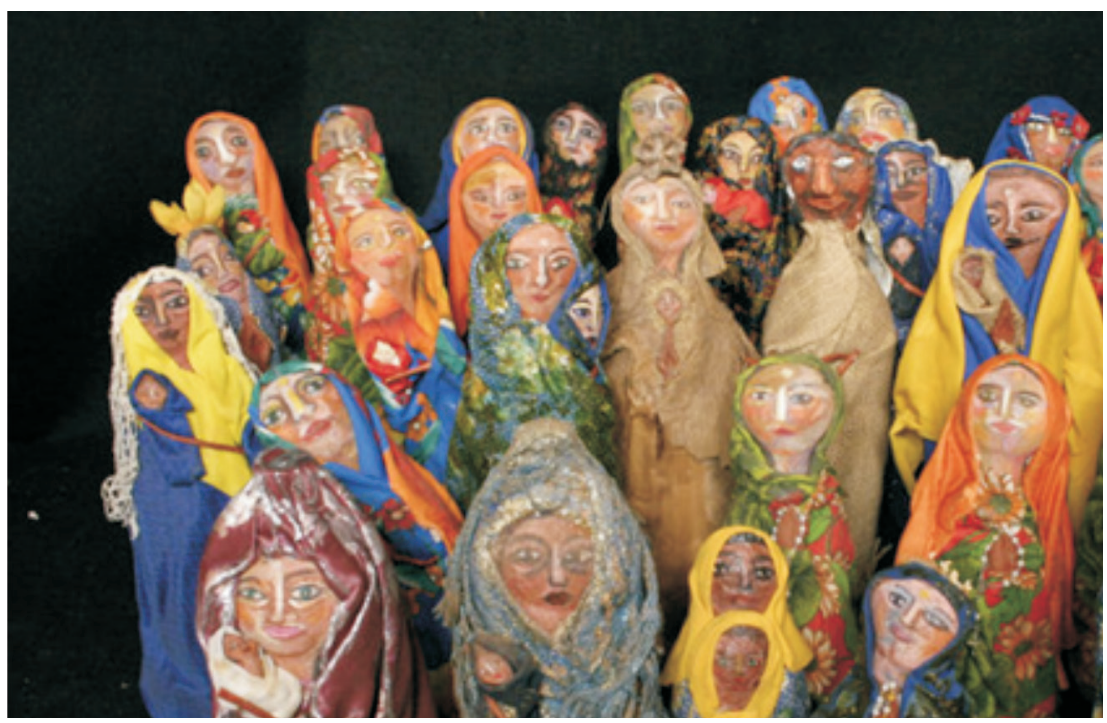

Fig. 1. Vitória Basaia - Série de Santas

Tecido, pets. 2006.

Na figura 1, podemos observar que se trata de uma série de santas. No centro, está a Virgem Maria segurando Jesus entre os braços e, ao seu lado, José, único homem da série, além de seu filho com "Deus". Segundo a mitologia hebraico-cristã absorvida, principalmente pelos cristãos, Jesus é filho de "Deus" e não de José, pois a fecundação que gerou sua vida foi realizada pelo Espírito Santo, sobrando a José a função de tutor da criança. Em volta da família, numa cena que nos lembra um presépio, ao invés de animais, estão diversas outras mulheres, muitas delas com seus rebentos no colo. Essas mulheres figurariam como santas? A artista escolhe dar forma a elas da mesma maneira que as santas, nos altares das igrejas, são moldadas. Pode haver uma relação entre as mulheres santas e a Virgem Maria? Se há esta relação, ela se dá pela gestação da vida e não pela virgindade, como se a artista quisesse demonstrar que todas as demais mulheres são santas, porque possuem o poder de gerar a vida em suas entranhas, mesmo sendo fecundadas por homens mundanos e não pelo Espírito Santo, tal qual a Virgem Maria. 
Essa leitura nos permite discutir a situação de castidade, que por muito tempo foi, e ainda é, em algumas culturas, imposta às mulheres antes do casamento como um sinal de pureza. Nesse caso, as mulheres santas de Vitória Basaia são obras produzidas a partir de materiais descartados, como garrafas plásticas revestidas por panos e tecidos, de uma forma similar a que ela criava seus brinquedos na infância, porém as técnicas foram aprimoradas pela pesquisa plástica que a artista inquietamente realiza.

O conteúdo associado a essa série pode ser fruto da vivência de Vitória, gravitando em sua natureza feminina, de gestar a vida e as suas obras, cuidar dos filhos, e, talvez em partes, pela educação religiosa católica que a artista recebeu em sua infância. Essa educação que, se antes era imposta a ela como um dogma, agora é questionada pela artista.

Sendo assim, por um lado, há uma conservação do traço subjetivo lúdico, despertado na infância pelo ambiente familiar e, por outro, têm-se novos elementos sendo incorporados gradativamente na rede subjetiva da artista, no decorrer de sua vida. Essa constante reconfiguração da subjetividade possibilitou que a sensibilidade artística de Vitória, existente na infância enquanto potência, se realizasse na vida adulta.

A Casa Basaia, como alguns nomeiam, é o local de moradia da artista que, ao mesmo tempo, abriga o seu ateliê e que, com o passar dos anos, acabou se transformando em um verdadeiro "museu". Essa casa é o pedaço de terra que abriga e sintetiza o universo poético da artista.

\section{COSMOgONIA: O PROJETO POÉTICO}

Quando entramos na Casa Basaia, percebemos logo que se trata de um mundo a parte. Vitória Basaia apresenta sua casa deste modo: "as coisas vão criando um sentido. Eu falo muito assim, eu chamo de cosmogonia, é assim o sentido que eu dou a esse universo que criei. Você entra aqui e é um universo a parte, ele tem uma energia criada" (BASAIA, 2012, entrevista). Em nossa interpretação, essa energia que emana do universo poético da artista pode ser relacionada com o bloco de sensações composto por afectos e perceptos, coforme a concepção de Deleuze e Guattari contida no livro O que é a filosofia? (1992, p. 213). Segundo os autores, a obra de arte é capaz de provocar sensações, perceptos e afectos:

Os perceptos não mais são percepções, são independentes do estado daqueles que os experimentam; os afectos não são mais sentimentos ou afecções, transbordam a força daqueles que são atravessados por eles. As sensações, perceptos e afectos, são seres que valem por si mesmos e excedem qualquer vivido (DELEUZE; GUATTARI, 1992, p. 213, grifo dos autores).

Os autores consideram que a arte é a única coisa que pode se conservar em si, com independência, inclusive do seu criador, pois "o que se conserva, a coisa ou a obra de arte, é um bloco de sensações, isto é, um composto de perceptos 
e afectos" (DELEUZE; GUATTARI, 1992, p. 213, grifo dos autores). Esses perceptos e afectos conservam-se na obra de arte e agem por bloco de sensações e atingem com o mesmo frescor do momento em que a obra ficou pronta, aqueles que estiverem em seu alcance.

São os perceptos e afectos que atacam e atravessam quem está em fruição diante ou, melhor dizendo, dentro da Casa Basaia. $\mathrm{O}$ fruidor é bombardeado pelas obras, que brotam, escorrem ou vazam por todos os lados, paredes e lugares. Nesse território, elas estão expostas e dispostas nas paredes, no chão e/ou em cima de todo o móvel que suscitar abrigo. Elas estão engendradas por toda a casa e com a casa, de maneira que, às vezes, estão fundidas no reboco da parede onde se destacam como esculturas (figura 2), e até mesmo no piso no qual se vê, ou se pisa, em um mosaico de cacos cerâmicos, cravados em meio ao piso bruto de cimento "queimado", que dá forma a um ser que nos remete a uma espécie de tartaruga (figura 3). A singularidade que essas obras carregam em sua forma atrai a atenção do expectador ou o provoca incômodo, atravessando-o com os perceptos e afectos em um bloco de sensações.

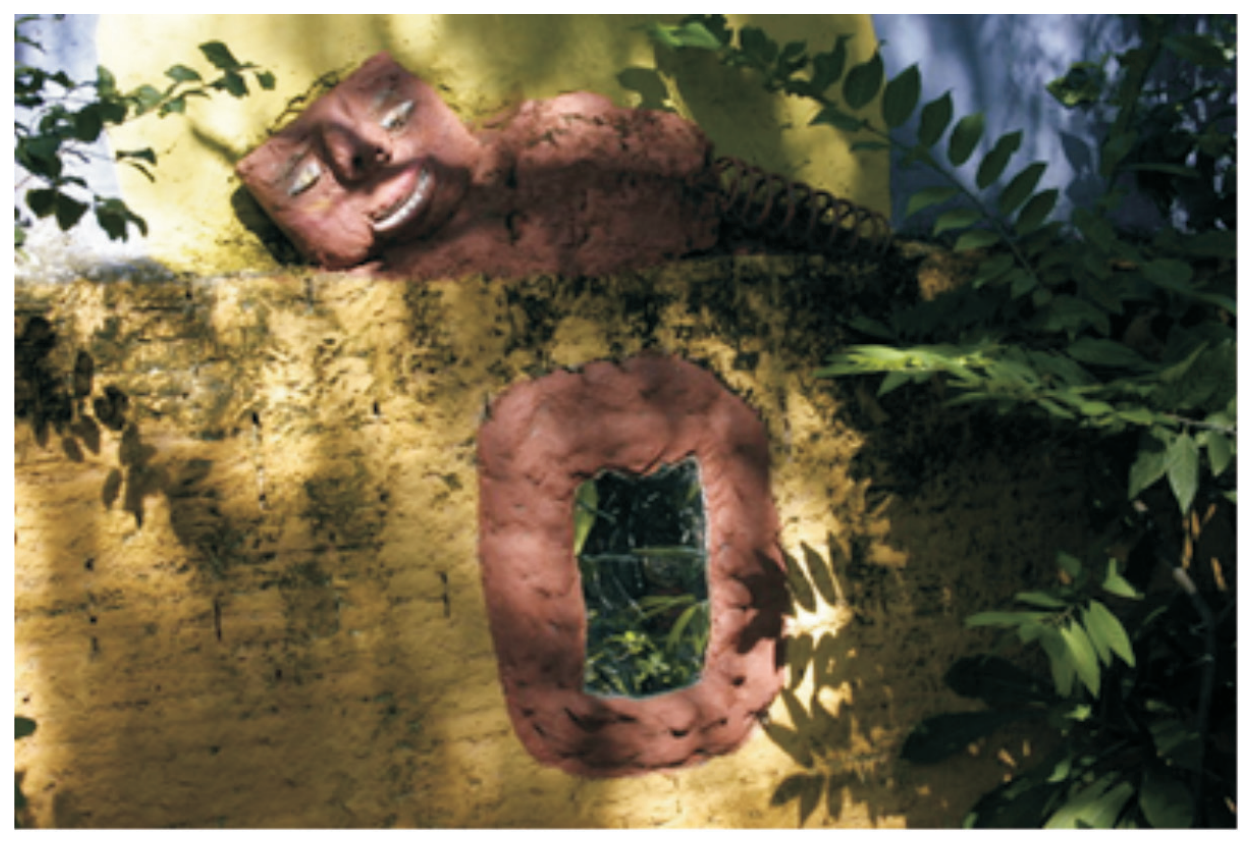

Fig. 2. Casa Basaia - Escultura, Jardim. 


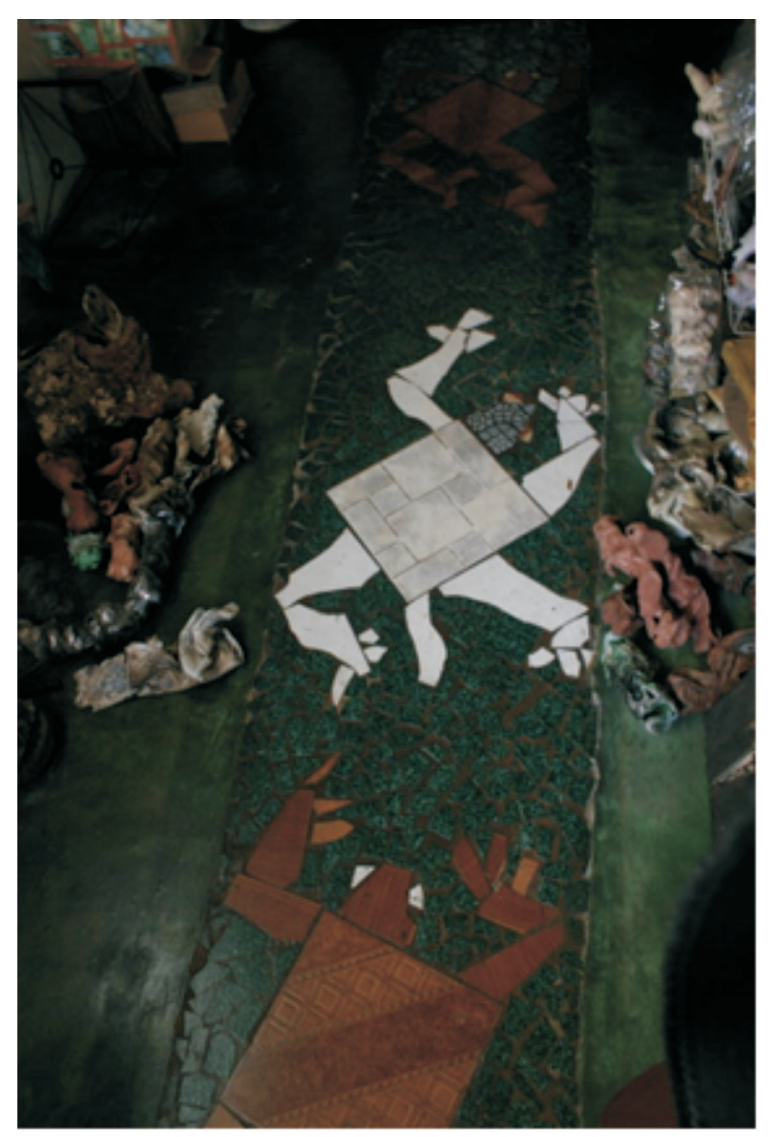

Fig. 3. Casa Basaia - Detalhe do Piso.

Mosaico e cimento queimado.

A artista age em seu projeto artístico, com o objetivo de criar um mundo, o seu universo. Para o estudioso em mitologia Mircea Eliade (apud CHEVALIER, 1993, p. 295-296) a cosmogonia é:

[...] o modelo exemplar de toda espécie de fazer. Não só por ser o Cosmos o arquétipo ideal ao mesmo tempo de toda situação criadora e de toda a criação, mas por ser uma obra divina. $\mathrm{O}$ Cosmos é, então, santificado na sua própria estrutura.

Percebemos que a cosmogonia de Vitória, em concordância com a afirmação de Eliade, está ligada ao fazer de toda forma. A artista ordena o caos em que a matéria prima se apresenta com suas leis especificas. Ela parte do trabalho para dar forma, construir e estruturar suas obras, em suma, fertiliza a matéria e dá vida as criaturas que antes não viviam (obras de arte), tal qual o Cosmos e por isso sua criação se torna sagrada assumindo um sentido divino em sua poética. Segundo a artista: 
Se você for pensar qual é a função da arte? Esteticamente, se você for falar, ela não tem função nenhuma, mas se você for falar pelo lado humano ela tem o poder de te transformar, porque as possibilidades que você pode ter. [...] Discutir qualquer assunto, do mais, assim, intrincado filosoficamente até as coisas mais banais. Como um simples ponto de fuga, né?!, Então eu acho que a arte é isso, né!? O artista... acho que ele tem uma benção especial de Deus, né?! Então essa coisa do encontro do matérico, tá dentro dessa coisa cósmica (BASAIA, 2012, entrevista).

Para Vitória, a arte possui uma dimensão cósmica que está contida no encontro material com o ser, a qual, realiza-se com o trabalho. Ao entender que o artista é abençoado por Deus, Basaia reforça o seu programa de arte concebido pela criação de mundos na formação de um universo próprio. Sua cosmogonia, como acontecem geralmente com todas as outras, se originam em um centro. A Casa Basaia é esse centro do mundo para Vitória. Segundo Eliade, "a casa é um microcosmos, do mesmo modo que a cidade é sempre um imago mundo. $\mathrm{O}$ umbral separa os dois espaços, o lar é assimilado ao centro do mundo" (ELIADE, 2008, p. 305, grifo do autor). A Casa Basaia se constitui um ambiente particular e paralelamente estranho a uma residência. Percebemos esse aspecto, na maneira em que os cômodos, mobiliário e estrutura da casa como as paredes, deixam de ser funcionalistas, no sentido da construção das casas modernas, para se reinventarem de um modo próprio de ser lavabo, copa, quarto etc.

Vitória contorna a produção de arte como representação do mundo ou de uma parte dele. A artista encapsula por instinto elementos que tenha sido deixado de lado, para, a partir desse refugo, inventar mundos distintos que constituem o seu universo poético. Dessa maneira, "diferentemente de artistas que recortam no mundo algo para ser explorado - uma matéria, um problema, um conceito, um delírio, um desejo, etc. -, Basaia está entre aqueles que se lançam no projeto de inventar mundos, do começo ao fim" (BRANDÃO, 2011, online). Notamos uma relação com o divino, com o sagrado na medida em que a artista se posiciona como uma produtora de mundos. Em Vitória Basaia a criação de arte contorna a mimética e se dá de maneira a criar imagens que buscam criar outras realidades, como produto de sua imaginação.

Em nossa interpretação, Vitória Basaia se singulariza por ser máquina criadora e por escolher a geração de vida ao invés da representação mimética do mundo pelas suas obras. Essa característica, de atuar em sua iconografia de outro modo que não a mimese, é observada também por Bertoloto que salienta: "jamais o rio é representado por ela na sua concepção mimética. Ele tem presença em sua obra por seu aspecto gerador de vida e de formas viscerais que se desenvolvem por seu intermédio" (BERTOLOTO, 2006a, p. 110). Bertoloto se refere a representação do rio Cuiabá por Vitória. O autor destaca que a artista nunca o representa mimeticamente. Em Basaia o rio assume um caráter de geração de seres que possuem formas viscerais que se harmonizam na construção dos enredos que contam a sua história e a da vida que se desenvolve em sua margem. Ainda 
sobre essa questão, Bertoloto (2006b, s/p) escreve em outra publicação: "obras que retratem não mimeticamente a natureza, mas sim todos os entrelaçamentos que decorrem dela e que para ela canalizem". Bertoloto, nesta última publicação, confirma a escolha pela não utilização da retratação da natureza pela mimese nas obras de Vitória. Ao contrário, o autor refere-se às obras como uma criação, produto das relações que são, na artista, canalizadas. $O$ efeito é o nascimento de uma série de narrativas ligadas a natureza e ao ambiente social em que o homem se insere.

Em sua obra Mil platôs: capitalismo e esquizofrenia, v. 1, os autores Deleuze e Guattari (1995, p. 18-21) apresentam o "Princípio de ruptura a-significante", que é uma das características aproximativas do rizoma. Para os autores, o rizoma concebe linhas de segmentariedade, que são estratificadas, territorializadas, porém, também compreendem linhas de fuga desterritorializantes. Essas linhas podem romper o rizoma, desestabilizando-o, contudo, ocorre sempre o risco da linha de fuga reencontrar uma organização que pode restituir o conjunto estratificando-o novamente. Os movimentos de territorialização e de desterritorialização, no rizoma, estão ligados uns aos outros. Os elementos se relacionam num devir, que tende por seu revezamento instigar as linhas de desterritorialização e ruptura. Nessa perspectiva os autores argumentam que:

O mimetismo é um conceito muito ruim, dependente de uma lógica binária, para fenômenos de natureza inteiramente diferentes. $\mathrm{O}$ crocodilo não reproduz um tronco de árvore assim como o camaleão não reproduz as cores de sua vizinhança. A pantera Cor-de-rosa nada imita, nada reproduz; ela pinta o mundo com sua cor, rosa sobre rosa, é o seu devirmundo, de forma a tornar-se ela mesma imperceptível, ela mesma a-significante, fazendo sua ruptura, sua linha de fuga, levando até o fim sua "evolução a-paralela" (DELEUZE; GUATTARI, 1995, p. 20).

A reflexão proposta por Deleuze e Guattari nos ajuda a pensar a maneira pela qual o modo de produção das obras de Vitória se agencia com o ambiente para frutificar sua iconografia. A artista não reproduz o mundo, mas se agencia com os seus elementos. Desse devir, produz-se rupturas com os significantes que estratificam seus temas, criando linhas de fuga que desterritorializam a representação, por exemplo, do rio Cuiabá, conforme o excerto de Bertoloto. Esta obra de Vitória singulariza o rio, cria linhas de fugas em um fluxo que expandem os limites de significação dele. Se ao contrário, a obra reproduzisse mimeticamente o rio produziria a manutenção da significação do rio estratificado, limitado de possibilidades.

Em resumo, a obra da artista se apresenta como um rizoma. Nela, existe recorrência de temas, porém com diversos tipos de materiais, formando uma imensidão de obras ou de peças resultadas dos exercícios plásticos de experimentação. Assim, a obra da artista compreende um conjunto, no qual, existe uma constante 
descoberta de formas e maneiras de criar artisticamente. É esse modo de produção, constituído por exercícios em que linhas de fuga que se engendram na teia criativa da artista, que possibilita a criação de seu um universo poético.

\section{A Casa Basaia: princípio, meio e fim}

A casa é o nosso canto do mundo. Ela é, como se diz amiúde, o nosso primeiro universo. É um verdadeiro cosmos. Um cosmos em toda a acepção do termo

(BACHELARD, 1993, p. 24).

Logo quando chegou ao Mato Grosso em 1981, Vitória Basaia passou uma temporada em um hotel na capital, de onde se mudou para uma casa no bairro Parque Cuiabá, imóvel que ora sofria com a falta de abastecimento público de água e ora com a abundância divina desse elemento que jorrava pelo teto através de goteiras, inundando a casa na época das chuvas. Ora, água de menos, ora, água de mais. Diante dessa situação, Vitória não pensou duas vezes e abandonou aquela casa. Ela retornou ao hotel com seus filhos, de onde julgou que não deveria ter saído e avisou Jota, ${ }^{1}$ seu marido, somente após a decisão já ter sido tomada e consumada.

Depois da breve estadia no hotel, a artista residiu em diversos imóveis em uma situação vulnerável de moradia que a obrigava a ter de se mudar de uma casa para outra em curtos períodos de tempo. Pela seguinte manifestação em tom de ultimato, Vitória estabeleceu o seu limite diante dessa situação e alertou Jota: "no próximo lugar em que a gente mudar, nós vamos ficar, nem que esse lugar seja uma tapera" (BASAIA, 2012, entrevista). Essas palavras saíram da boca de Vitória como uma profecia, que se concretizou em 1985, com a compra e ocupação da Casa Basaia, na cidade de Várzea Grande, região metropolitana de Cuiabá.

A casa foi considerada uma tapera pela artista, pois os aspectos que geralmente devem ser considerados na compra de um imóvel, tal qual o tamanho em metros quadrados, o tempo de construção e o acabamento ficaram em segundo plano. O elemento de destaque para o fechamento do negócio foi o fato de que no quintal da casa havia um Pé de Pequi: árvore típica do cerrado e considerada um símbolo da cultura Goiana. Jota é goiano e por isso comprou aquela casa, mesmo sendo considerada por Vitória uma tapera. Nas palavras da própria artista "Jota não comprou uma casa, comprou um Pé de Pequi” (BASAIA, 2012, entrevista).

O Pé de Pequi após quebrar as telhas da "casa-tapera", com seus minguados frutos, foi sacrificado por Vitória que colocou em seu caule uma solução composta por cal e água quente. Até hoje o Pé de Pequi está na casa, porém apenas o seu tronco sobreviveu ao ataque da artista. Apesar de ter sido o Jota quem escolheu a "casa-tapera", justamente por nela haver um Pé de Pequi, fator simbólico que o ligava a sua origem goiana, foi Vitória quem tomou conta da casa.

Desse modo, Vitória sepultou simbolicamente a ligação daquele espaço com o passado e com a história que o casal vivera em Goiânia. Agora, o Pé de Pequi está morto, porém renascido, já que o seu caule ainda está lá, na casa, 
indicando que houve uma ligação do casal com Goiânia, mas que essa relação não dá mais frutos. Ciclo de morte e vida que dá espaço para construção do universo de Vitória na "casa-tapera".

Bachelard (1993, p. 24) alerta, em seu livro A poética do Espaço, que existem vários problemas a serem enfrentados por aqueles que quiserem "determinar a realidade profunda de cada uma das nuanças do nosso apego a um lugar predileto!". Para Bachelard, essas nuanças não são superficiais, necessitando ser encaradas como um fenômeno psicológico estrutural. Concordando com essa afirmação, notamos que não é tarefa fácil pesquisar e transformar em texto científico a complexidade do conjunto de nuanças da afeição de alguém por um lugar preferido.

Ainda sobre essa questão, Bachelard (1993, p. 24) afirma que "não se trata de descrever casas, de pormenorizar-lhes os aspectos pitorescos e de analisar as razões do seu conforto. É preciso, ao contrário, superar os problemas da descrição". A partir da concepção de Bachelard, percebemos que o modo como conduzimos o trabalho de campo nos possibilitou viver, em alguma dimensão, os devaneios da Casa Basaia. Esse caminho nos revelou algumas virtudes da casa, que não seriam explicitas se nos preocupássemos apenas com as suas minúcias. Portanto, nossas visitas a campo foram realizadas sem a preocupação em descrever subjetiva ou objetivamente a Casa Basaia, mas sim, cativados pela possibilidade de vivermos uma amostra de seus devaneios, ocorridos tanto na experiência das suas linhas de segmentariedade, quanto nos momentos de perda de rumo pela casa, caminhando por essa como em um labirinto. Nessa trajetória as linhas de fuga nos levaram, por vezes, para lugares distantes daqueles que tínhamos pré-determinado em nosso roteiro de pesquisa e por outras, nos trouxeram de volta a ele.

Essa dimensão de nosso trabalho de campo foi inspirada e se aproxima da noção de mapa dos autores Deleuze e Guattari. Esse conceito contribui para justificar o nosso método de pesquisa, pois os autores pensaram no mapa como uma forma de construção, em oposição ao decalque que, para eles, significa um instrumento fechado sobre si mesmo, nas palavras dos autores: "se o mapa se opõe ao decalque é por estar inteiramente voltado para uma experimentação ancorada no real. O mapa não reproduz um inconsciente fechado sobre ele mesmo, ele o constrói" (DELEUZE; GUATTARI, 1995, p. 22). Por esse prisma, sabemos que fizemos uma escolha por um percurso durante essa pesquisa e a partir dele construímos esse artigo. Temos certeza que outros pesquisadores, caso escolhessem o mesmo objeto, percorreriam caminhos diferentes do nosso, ou até mesmo parecido. Isso é possível graças a Casa Basaia ser rizomática, ou seja, por ela permitir o pesquisador transitar de diferentes formas pelo seu território possibilitando escolher as entradas e as saídas.

Relacionamos a concepção de multiplicidades de Deluze e Guattari com a Casa Basaia. De acordo com os autores: "as multiplicidades se definem pelo fora: pela linha abstrata, linha de fuga ou de desterritorialização segundo a qual elas mudam de natureza ao se conectarem às outras. $\mathrm{O}$ plano de consistência (grade) é o fora de todas as multiplicidades" (DELEUZE; GUATTARI, 1995, p. 17). Portanto, as dimensões podem ser complexificadas pelas linhas de 
fuga que desestabilizam o conjunto, ou seja, é a multiplicidade que produz a desterritorialização quando ela se conecta com o ambiente territorializado. A Casa Basaia é um território relacionado com a multiplicidade por meio das linhas de fuga que desterritorializam a significação de seus espaços na convenção da casa ocidental. Seus cômodos se reinventam na tentativa de serem diferentes, na busca da singularização. Contudo, percebemos essa singularidade em todos os cômodos o que, de certa forma, achata as multiplicidades da casa em um plano de consistência que territorializa as dimensões da casa num pilar fundamentado na criação e na parição das obras que compõem esse universo poético.

A casa se torna múltipla de dimensões na medida em que ela abriga Vitória e a sua família, portanto é moradia, mas, ao mesmo tempo, é o ateliê artístico, é ali que a artista produz suas obras. As obras, por sua vez, estão expostas em quase todos os cômodos como em um museu, todavia há um acervo de peças que se destinam a venda o que a configura, também, como galeria de arte, sem falar nas intervenções que a artista realizou nela. Seria então, a própria Casa Basaia, também obra de arte? Segundo Ludmila Brandão (2011, online), em referência a casa da artista:

De saída, haveremos de lidar com a natureza inclassificável desse espaço: Museu? Galeria? Ateliê de artista? Casa? Obra plástica? Ainda que persiga a especialização convencional da casa ocidental moderna, com salas, quartos, copa-cozinha, banheiros, varandas, depósitos, jardins, percebemos o esforço do gesto que, em cada canto, quer inventar um modo próprio de ser espaço, de ser quarto, cozinha, banheiro. De ser um lugar, singular.

Observamos, durante a pesquisa de campo na Casa Basaia, o esforço no gesto da artista em inventar e construir um modo próprio de cada cômodo ser espaço singular (figuras 4 e 5), e da soma, desses espaços, compor o seu universo artístico. Como máquina criadora, Vitória, também, não se contenta em possuir uma relação convencional com seus móveis e utensílios. Por isso ela imprime neles uma intervenção que os envolve de sentido singular, e ao mesmo tempo coerente com sua cosmogonia.

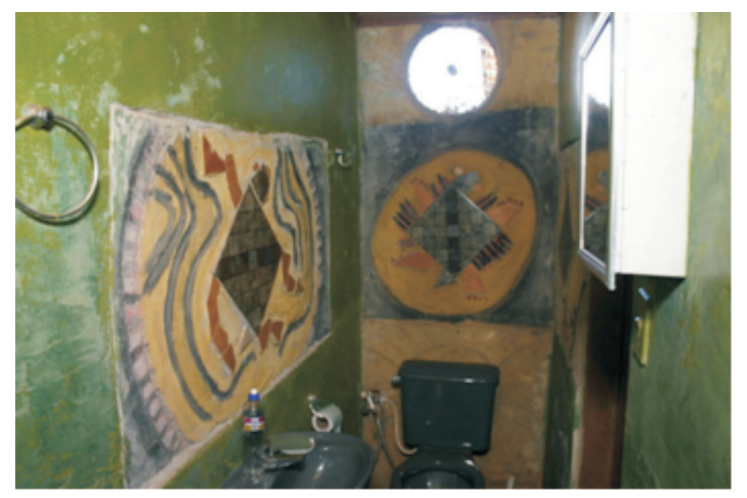

Fig. 4. Casa Basaia - Lavabo. 


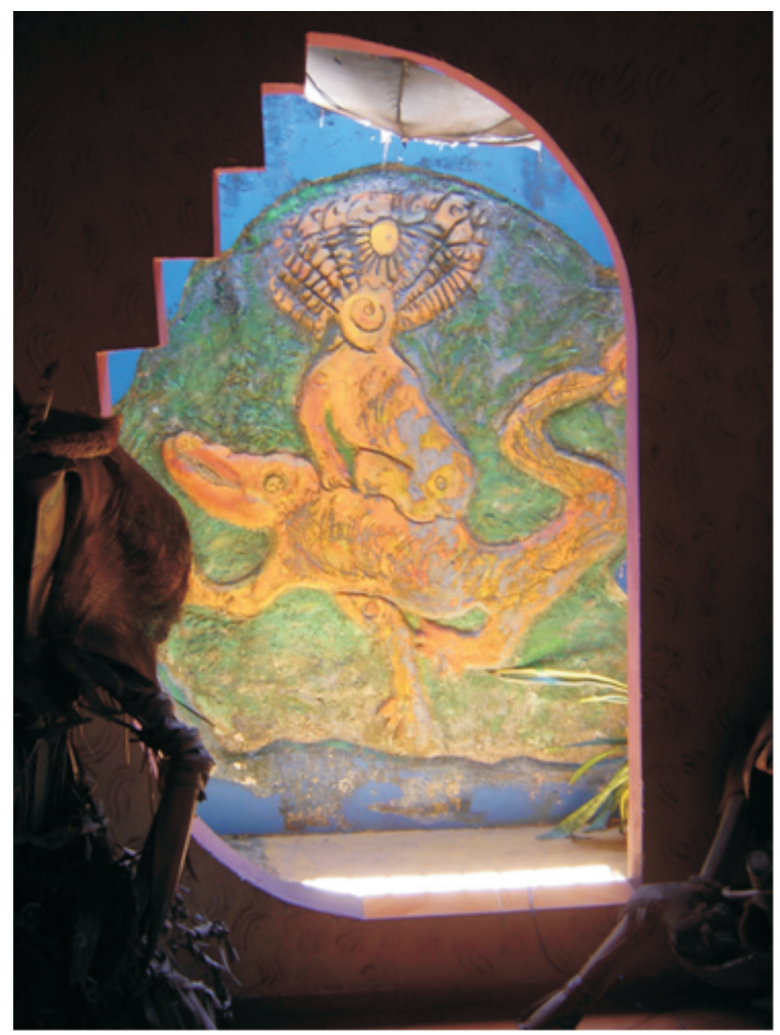

Fig. 5. Casa Basaia - Painel, Jardim de inverno.

Assim cada espaço físico, cada mobília compõe e constrói o seu território existencial. Segundo Ludmila Brandão (2002, p. 64):

O território se constitui quando emergem matérias de expressão. Quando os componentes de meios além de deixarem de ser direcionais para serem dimensionais, deixam de ser funcionais para serem expressivos. A expressão é, por conseguinte, a marca territorial, a assinatura, resultado de uma combinação entre constância temporal e alcance espacial.

Como resultado, esse território criado pela artista expõe matérias diversas que apontam para um sentido singular capaz de provocar os moradores e visitantes. $\mathrm{Na}$ Casa Basaia os objetos são muito mais do que funcionais (ou nem funcionais são) e, sobretudo, são expressivos. A capa de um sofá, por exemplo, abriga um desenho no qual uma das mulheres de Vitória vive com uma vagina metamorfoseada junto e no lugar da orelha. A figura de uma vagina retoma, conforme demonstrado neste trabalho, a arte como parição, projeto poético da artista. 
A expressão tem autonomia, e se revela nas relações que as matérias expressivas estabelecem ora entre si, ora com as circunstâncias externas. Nestas relações, são exploradas as potencialidades dos meios, interior ou exterior, e aqui se constata que o território, ao contrário do que sempre nos parece, é um lugar de passagem, porque nele tem ocasião a formação de novos agenciamentos, inclusive desterritorializantes (BRANDÃO, 2002, p. 66, grifo da autora).

Todos os elementos, materiais ou não, que atravessam a casa, são potentes e expressam o mundo encantado da artista, infiltram-se nesse território e/ou explodem pelo lado de dentro (figuras 6 e 7). Se pensarmos na matéria em transito pela casa, perceberemos que ela ativa a imaginação de Vitória, contribuindo com a construção de seu universo ou desterritorializando-o com suas linhas de fuga. Assim, reafirmamos nossa compreensão de que a Casa Basaia é rizomática, pois "a casa-rizoma não é objeto. Não se desloca dos homens como aquele que sofre a ação. Homem e espaço doméstico confundem-se" (BRANDÃO, 2002, p.33). Reconhecemos que Vitória é a própria Casa Basaia, artista e espaço se confundem criando um território poético.

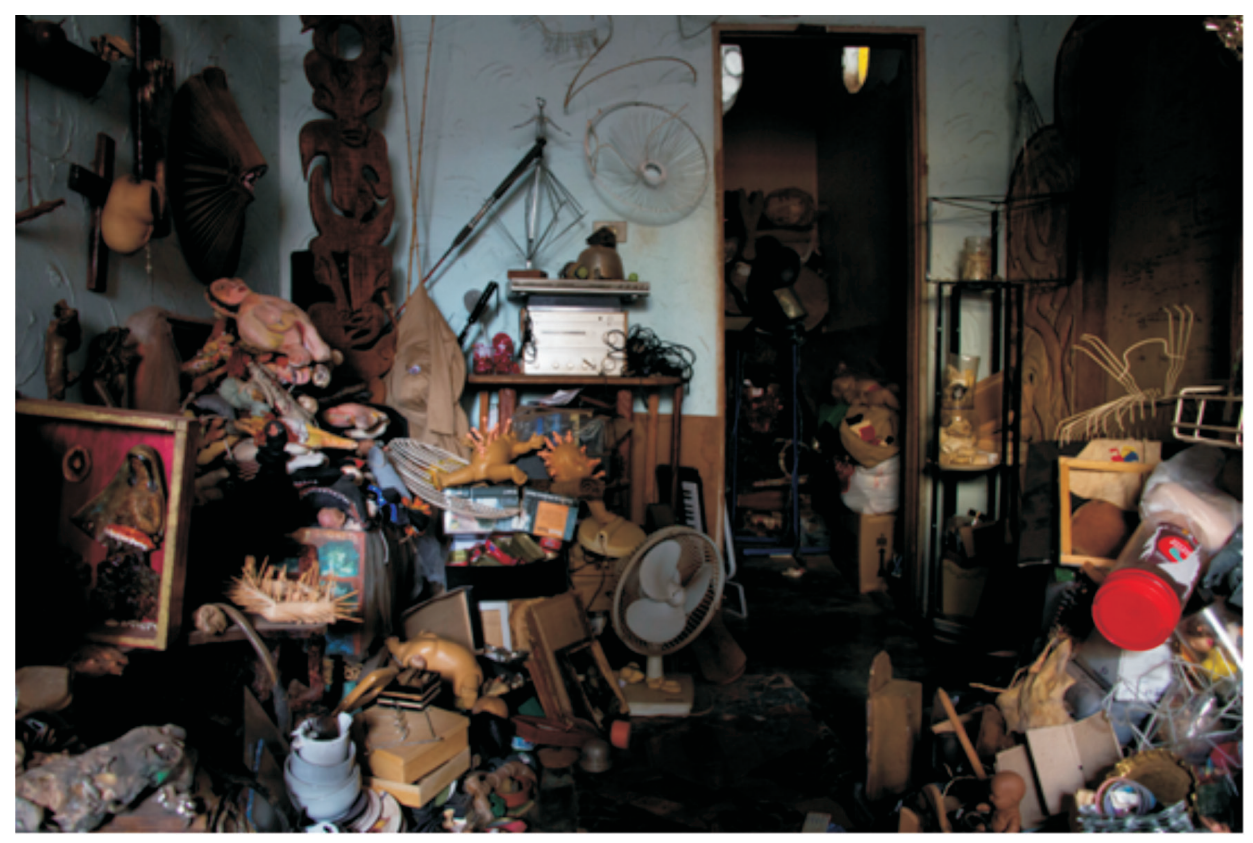

Fig. 6. Casa Basaia. Laboratório plástico, "Ventre Criativo". 2013. 


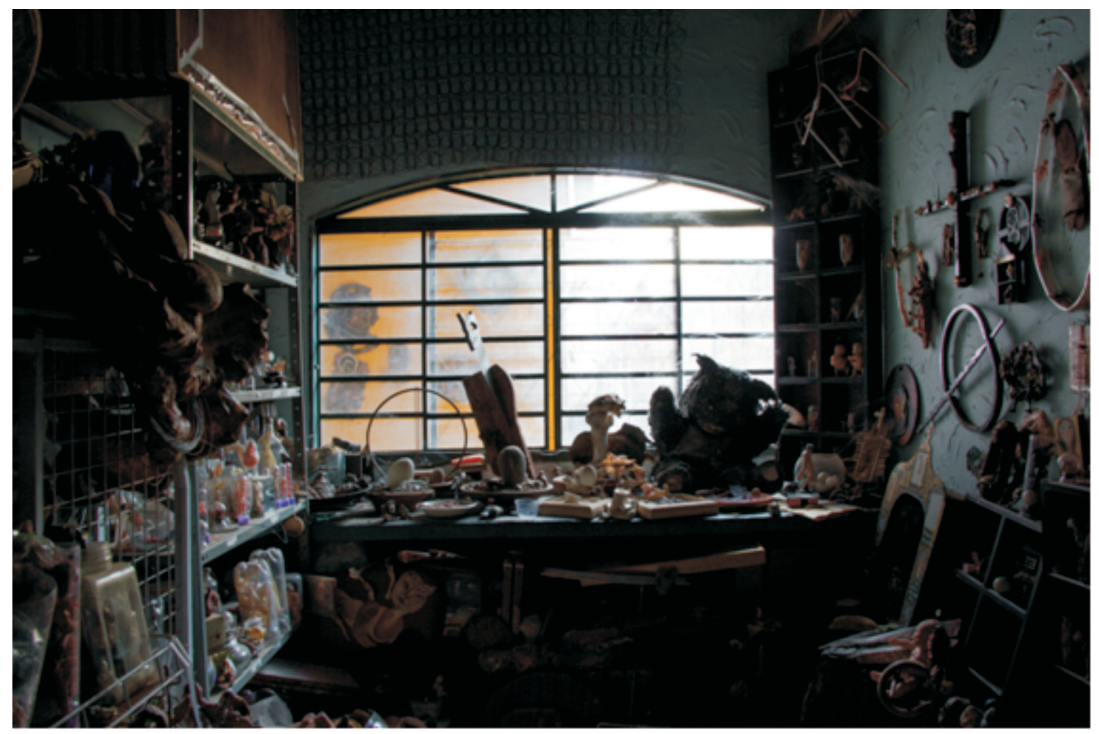

Fig. 7. Casa Basaia. Laboratório plástico, "Ventre Criativo". 2013.

De acordo com Deleuze e Guattari: "todo rizoma compreende linhas de segmentariedade segundo as quais ele é estratificado, territorializado, organizado, significado, atribuindo, etc.; mas compreende também linhas de desterritorialização pelas quais ele foge sem parar" (DELEUZE; GUATTARI, 1995, p. 18). A Casa Basaia, possui uma dimensão estratificada, ela é território organizado pela poética de Vitória. Apesar disso, diversos elementos externos, como, por exemplo, os materiais descartados que são recolhidos pela artista, desestabilizam o conjunto atribuindo a ele novas dimensões pela conexão com a multiplicidade pelas linhas de fuga que esses objetos produzem.

A Casa Basaia possui um papel fundamental para Vitória e na trama de sua poética ela é o território em que Basaia constrói seu universo artístico. Um universo em expansão no qual lançou seus tentáculos por todos os espaços da casa, numa inquietante criação. Sua obra tomou todos os cômodos, todas as paredes - internas e externas, o jardim, o depósito, a garagem e a fachada (figuras $8,9,10,11$ e 12). Nada escapou ao seu movimento criador, com apenas uma exceção: uma cadeira na cabeceira da mesa de jantar. Fomos alertados seriamente pela artista (nos primeiros dias da pesquisa de campo), que ninguém poderia se sentar naquela cadeira, pois a mobília era o único móvel da casa de propriedade do seu marido Jota e, somente ele poderia naquela cadeira se sentar. 




Fig. 8. Casa Basaia - Escultura, Jardim.

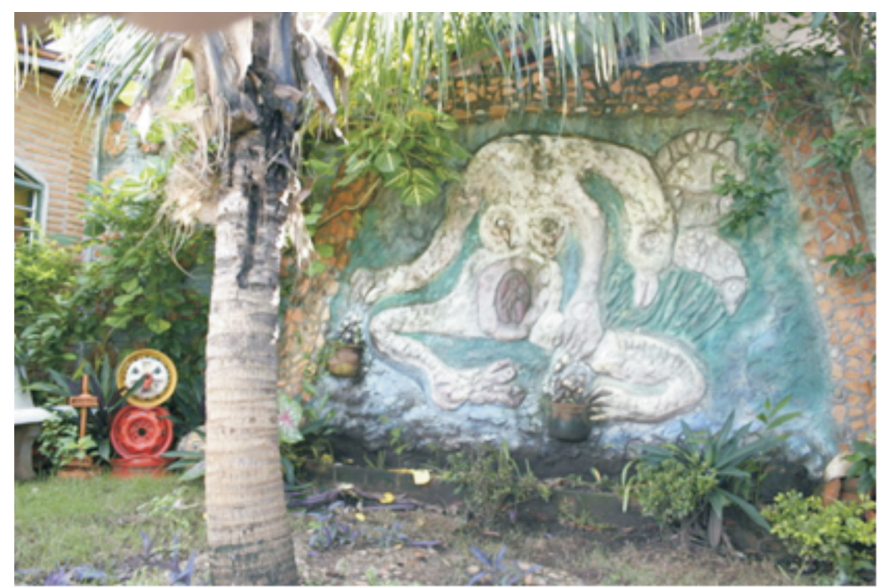

Fig. 9. Casa Basaia - Painel, Jardim.

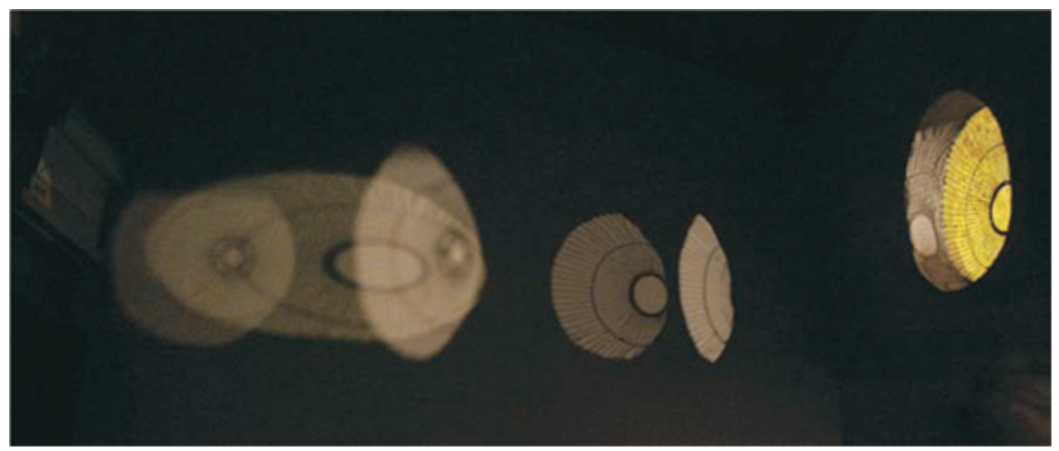

Fig. 10. Casa Basaia - Escultura de Luz, Série Proposta Conceitual, Sombra e Luz. Técnica mista. 


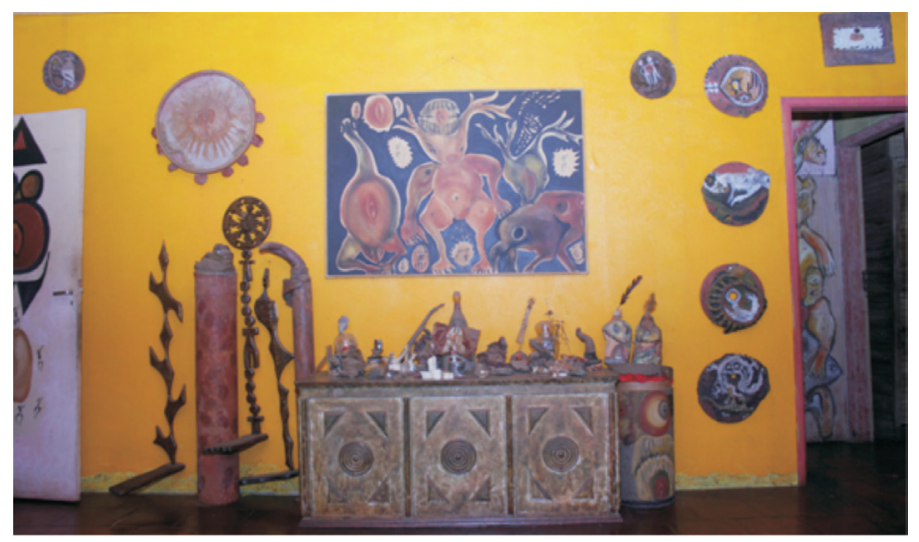

Fig. 11. Casa Basaia - Sala.

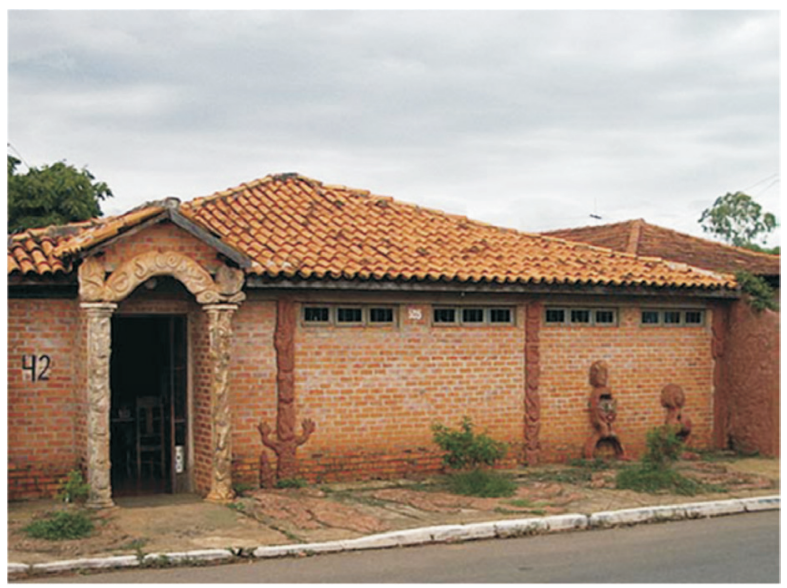

Fig. 12. Casa Basaia - Fachada.

Nesse ato, Vitória deixa escapar a consciência de que a casa é o seu território e vive sobre o seu reinado, e que cabe a quem convive intimamente, em meio a esse universo, somente uma ilha livre de sua intervenção, uma cadeira na cabeceira da mesa de jantar. Percebemos com essa experiência que a casa é um território dominado por Vitória e por suas obras. A artista, ao construir a Casa Basaia, constrói a si mesma e, nesse movimento, a casa passa a ser suporte de inúmeras obras e, principalmente, ela própria uma obra. Segundo Ludmila Brandão:

Na sucessão das obras que começamos a ver desde a fachada da casa até o muro do fundo do quintal, passando por espaços amplos, outros exíguos, de onde explodem, escorrem, vazam peças de todos os tamanhos e de mais variadas formas/ materiais, descobrimos uma outra obra, maior, inapreensível, irrequieta, a própria casa, a casa Basaia, aquela que abriga, rebate ou compõe o universo fantástico de Vitória Basaia, artista (BRANDÃO, 2011, online). 
Durante décadas, num trabalho artístico inquietante, Vitória tomou os cômodos de seu lar, um a um, com suas obras, interviu artisticamente na casa onde foi possível. Ao realizar essa ação, a artista criou uma obra maior, a Casa Basaia, que é a materialização do seu próprio ser artístico. Essa grande obra conserva em si a inquietude do universo poético da artista e, por consequência, se transmuta na própria Vitória Basaia.

Findamos afirmando que a Casa Basaia, como território organizado pela poética de Vitória, é a síntese de seu projeto poético. A casa abarca suas linhas de fuga, é seu espaço vital, sua raiz e seu céu, seu chão e seu teto é, parafraseando Bachelard, seu "canto do mundo".

\section{Nota}

${ }^{1}$ Optamos por manter a forma que Vitória Basaia se refere ao seu marido Júlio César de Carvalho: Jota. 


\section{REFERÊNCIAS}

BACHELARD, G. A poética do espaço. Tradução de Antonio de Pádua Danesi. São Paulo: Martins Fontes, 1993.

BASAIA, V. Vitória Basaia: depoimento. Várzea Grande, 2012. Entrevista de campo.

BERTOLOTO, J. S. Iconografias das águas: o rio e suas imagens. Cuiabá: Carlini \& Caniato; Cathedral, 2006a.

BERTOLOTO, J. S. Do universo inquieto de Vitória Basaia: arqueologia urbana. Cuiabá: Macp - UFMT, 2006b. Não paginado.

BRANDÃO, L. de L. A casa subjetiva. São Paulo: Perspectiva, 2002.

BRANDÃO, L. A Casa Basaia. 10 fev. 2011. Disponível em: <http://vitoriabasaia. blogspot.com.br/>. Acesso em: 07 ago. 2011.

CHEVALIER, J. Dicionário de símbolos: mitos, sonhos, costumes, gestos, formas, figuras, cores, números. Tradução de Vera da Costa Silva. Rio de Janeiro: José Olympio, 1993.

DELEUZE, G. GUATTARI, F. O que é a filosofia? Tradução de Bento Prado Jr. e Alberto Alonso Muniz. Rio de Janeiro: Ed. 34, 1992.

DELEUZE, G. GUATTARI, F. Mil platôs: capitalismo e esquizofrenia. Tradução de Aurélio Guerra Neto e Célia Pinto Costa. Rio de janeiro: Ed. 34, 1995. v. 1.

ELIADE, M. Tratado de História das Religiões. São Paulo: Martins Fontes, 2008.

PAREYSON, L. Os Problemas da Estética. São Paulo: Martins Fontes, 2001.

Recebido em: 02 de julho de 2014 Aceito em: 03 de setembro de 2014 